\title{
Visibilidade e Legitimidade na Atual Ecologia Midiática
}

\author{
Eugenia Maria Mariano da Rocha Barichello \\ Universidade Federal de Santa Maria \\ eugeniabarichello@gmail.com
}

\begin{abstract}
Resumo
Minha investigação tem como pressuposto o fato de que as tecnologias de informação e comunicação e seus usos sociais têm alterado as possibilidades de ver e de ser visto, de interagir à distância, de representar e identificar o real, fenômenos que repercutem nos processos de institucionalização e obtenção de legitimidade das práticas sociais, incluindo as do próprio campo midiático. As noções de visibilidade e legitimidade de atores individuais e coletivos (comunidades, organizações) despertaram meu inte-

resse há mais de uma década. Essas noções têm uso corrente em outros campos do saber, como a sociologia, a filosofia e a antropologia, e as considero pertinentes para estudar aspectos fundamentais das práticas e ambiências comunicativas contemporâneas. As relações entre indivíduos, instituições e organizações, tanto no contexto macro como em práticas em nível mais localizado, podem encontrar um respaldo teórico importante nos pensadores da teoria, reconhecida mundialmente, como Media Ecology.
\end{abstract}

Keywords: visibilidade midiática; visibilidade e legitimidade; ecologia midiática.

\begin{abstract}
My research has as a presupposition the fact that information and communication technologies and their social uses have altered the possibilities of seeing and being seen, of interacting at a distance, of representing and identifying the real, phenomena that have repercussions on the processes of institutionalization and Legitimacy of social practices, including those of the media field itself. The notions of visibility and legitimacy of individual and collective actors (communities, organizations) have

aroused my interest for more than a decade. These notions are commonly used in other fields of knowledge, such as sociology, philosophy, and anthropology, and I consider them relevant to study fundamental aspects of contemporary communicative practices and environments. Relationships between individuals, institutions, and organizations, both in the macro context and in more localized practices, may find important theoretical support in the thinkers of the theory of Media Ecology.
\end{abstract}

Keywords: media visibility; visibility and legitimacy; media ecology.

A Revista Estudos em Comunicação é financiada por Fundos FEDER através do Programa Operacional Factores de Competitividade - COMPETE e por Fundos Nacionais através da FCT - Fundação para a Ciência e a Tecnologia no âmbito do projeto Comunicação, Filosofia e Humanidades (LabCom.IFP) UID/CCI/00661/2013.

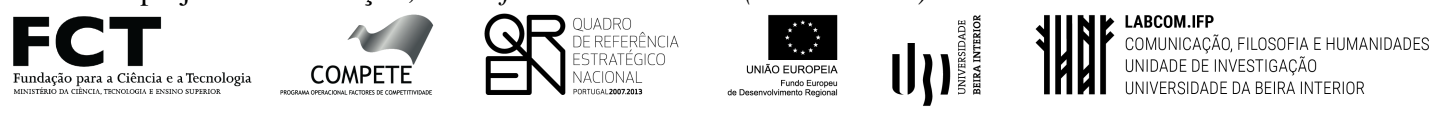




\section{Introdução}

$\mathrm{E}^{\mathrm{s}}$ TE texto está dividido em três partes; a primeira trata da Onipresença midiática, visibilidade e legitimidade, aborda as noções de visibilidade (Foucault 1996) e legitimação (Berger e Luckmann 1997) como parte de um dispositivo maior, denominado vigilância (Foucault 1996). A segunda, denominada Os meios como ambientes culturais na Ecologia Midiática traz uma breve reflexão sobre os conceitos aqui discutidos diante de uma nova Ecologia Midiática (Scolari 2012). $\mathrm{E}$, ao final, apresento alguns comentários pontuais sobre as reflexões realizadas no texto.

Meu lugar epistemológico é o das ciências da comunicação, um campo híbrido e novo. Assim, por meio de aportes de outras áreas das humanidades procuro entender e dar sentido às práticas midiáticas da atualidade. Ajustando o foco, posso dizer que meu olhar privilegia a comunicação midiática, ou seja, elaboro investigações, reflexões e análises, utilizando como substrato a mediação técnica. Estas escolhas são justificadas, em parte, pelo fato de que o Programa de PósGraduação em Comunicação da Universidade Federal de Santa Maria, RS, Brasil (UFSM), tem como área de concentração a Comunicação Midiática, que compreende o estudo da ação dos media implicada na estruturação do espaço público, na visibilidade e legitimação das instituições e na configuração das identidades contemporâneas.

Explicada esta filiação, esclareço que trabalho com o pressuposto de que as tecnologias de informação e comunicação e seus usos sociais têm alterado as possibilidades de ver e de ser visto, de interagir à distância, de representar e identificar o real, fenômenos que repercutem nos processos de institucionalização e obtenção de legitimidade das práticas sociais, incluindo as do próprio campo midiático.

Aos estudos realizados em meu doutorado e nas investigações que o sucederam adicionei a proposta de que as relações entre indivíduos, instituições e organizações, tanto no contexto macro como em práticas em nível mais localizado, podem encontrar um respaldo teórico importante na escola de pensamento denominada Media Ecology, que possui representantes distribuídos em países como o Canadá (McLuhan 1962,1964), Estados Unidos (Sternberg 2014), Espanha (Scolari 2012), Portugal (Canavilhas 2014, 2015), Brasil (Barichello 2013; Pereira 2004) e Argentina (Vizer 2012), considerando apenas os autores com os quais tenho dialogado mais em minhas pesquisas.

Para tentar superar a dicotomia entre humano versus tecnologia tenho utilizado, cada vez mais, o entendimento da tecnologia como artefato cultural (Horst e Miller 2012) e, portanto, produto da experiência (Rodrigues e Braga 2014) humana e das relações sociais. Assim, nos processos comunicacionais que tenho investigado, é cada vez necessário utilizar metodologias de pesquisa que contemplem as relações estabelecidas em ambientes on-line e off-line e os processos de construção de vínculos de reconhecimento entre indivíduos, grupos e organizações sociais, já que os resultados obtidos com as investigações vão sustentando que essas ações e relações coexistem e estão interconectadas. Diante dessas considerações, é possível perguntar: Como pensar hoje a visibilidade proporcionada pelos media e como se dá este processo, bem como o processo de legitimação, no contexto da atual ecologia midiática? 
As noções de visibilidade (associada ao poder) e de legitimidade (referente ao reconhecimento) de atores coletivos e individuais continuam sendo centrais e necessitam ser compreendidas diante das lógicas e fluxos de interação da sociedade atual. Comecei a investigar primeiro a noção de legitimidade e suas ligações com o reconhecimento institucional, o que me conduziu ao estudo das relações entre o processo de reconhecimento e a necessidade de publicização de ações. Esses estudos me levaram à investigação dos processos de formação da opinião pública, de construção da "visibilidade midiática" e chegar ao estágio atual no qual tenho estudado estes processos na sociedade contemporânea, marcada pela interação não presencial. O que me leva a pensar que as reestruturações das relações entre indivíduos, instituições e organizações, tanto no contexto macro como em práticas em nível mais localizado, podem encontrar um respaldo teórico importante no cenário atual, na escola de pensamento denominada Media Ecology.

A demanda por novas abordagens teórico-metodológicas provem, especialmente, das investigações que tomam por objeto empírico, de uma maneira geral, a comunicação em suportes digitais e, mais especialmente, as transformações das relações comunicacionais na atualidade. A apropriação e o uso da tecnologia em um lugar e cultura particulares são questões que demandam investigações, pois as ações comunicacionais e culturais estão conectadas na sociedade real, como é possível verificar nos acontecimentos midiáticos contemporâneos, como os movimentos e as reivindicações de cunho social e político, que têm ocorrido no Brasil e em vários outros países e que ocorrem, simultaneamente, nas ruas, nas redes sociais digitais e nas mídias hegemônicas.

A primeira geração de estudiosos sobre a internet costumava defini-la como um não lugar, caracterizado por práticas sociais transformadoras ou mutantes. Os estudos que sucederam esta primeira geração de estudiosos da internet foram aproximando cada vez mais a compreensão das atividades exercidas pelos indivíduos em ambientes on-line e off-line, constatando que a internet não se constitui em um 'ciberespaço' monolítico (Miller e Slater 2001: 100; Miller 2009) ou um não lugar, mas é formada por numerosas tecnologias utilizadas por diversas pessoas, em diversos lugares.

Meu pressuposto é que a mídia é um artefato cultural que, atualmente, permeia de tal forma a sociedade que não se pode mais considerá-la como algo separado das instituições e organizações. O fato é que os meios de comunicação não podem mais ser entendidos como meras ferramentas que as instituições, organizações e indivíduos utilizam para atingir seus fins, pois a mídia tornou-se parte do tecido social e também uma instituição independente, num processo que afeta instituições, organizações e indivíduos em suas relações e interações. Ou seja, as questões tradicionais sobre o uso e os efeitos da mídia, precisam, atualmente, considerar a mediação técnica exacerbada e a minha questão recorrente tem sido desvelar quais as maneiras pelas quais instituições, organizações e indivíduos configuram novos processos estratégicos para obter visibilidade e legitimação de suas práticas e, ao atuar nessas novas ambiências, parecem reconfigurar as interações sociais.

Reitero que o meu olhar vem da comunicação dita midiática. Tenho formação disciplinar, desde a graduação, neste tipo de comunicação. No Brasil, nosso campo acadêmico nasceu dentro das faculdades de filosofia, com professores da sociologia e da antropologia e outras áreas. Este fato é louvável pela pluralidade, mas, por outro lado, levou durante décadas (desde 1948) a ensinarmos os alunos a apenas criticar os media. Com a experiência atual do campo cabe, agora, 
entender o sistema midiático de cada tempo, especialmente o deste tempo, para pôr em comum o que é para ser posto em comum e criar vínculos em novos tempos e espaços.

\section{Ubiquidade Midiática, Visibilidade e Legimitidade}

Atualmente, a ubiquidade dos media e a vigilância (consentida) estão presentes em nosso cotidiano. As interações sociais estão sujeitas a uma avaliação em tempo real, que pode ser convertida em mais acessos e vantagens sociais ou em segregação.

As revelações de Snowden sobre a vigilância massiva nos EUA revelaram ao mundo os usos políticos, sociais e econômicos dessa vigilância indiscriminada. A popularidade nas redes tornase moeda social em tempo real. A monetização dos youtubers, celebridades e anônimos torna-se norma, com contabilização dos afetos e interações. Os comportamentos podem ser vigiados e avaliados em tempo real.

Na década de 1990, Gilles Deleuze analisou a sociedade disciplinar e relacionou-a as configurações sociais daquele momento. Para ele, a partir da metade do século XX, as sociedades disciplinares foram substituídas pelas sociedades de controle, que atuam por controle contínuo e comunicação instantânea (Deleuze 2013: 219).

Atualmente, a comunicação digital permite que o exercício do poder aconteça de forma contínua, porque prescinde da presença física e da instantaneidade para se efetuar. Cuida-se de cada um individualmente e, de todos, ao mesmo tempo. A assinatura e o número de matrícula foram substituídos pela senha, que dá acesso à informação (Deleuze 2013: 2). A senha permite a entrada no mundo digital, onde as informações on-line podem ser acessadas, armazenadas e analisadas. Ter uma senha de acesso ao ambiente digital permite a inserção numa parte significativa do processo informacional e comunicacional nos dias de hoje.

O dispositivo de vigilância digital tem três pontos centrais: a informação, os bancos de dados e os perfis computacionais (profiles) (Bruno 2008: 154), aos quais acrescento um quarto ponto: os relacionamentos. A informação é a matéria-prima; é sobre ela que se dá a vigilância. Os bancos de dados permitem registrar a informação, a qual pode ser então, acessada quando necessário. Os perfis computacionais viabilizam gerar conhecimento sobre os processos de individualização e produção de identidades (Bruno 2008: 170). Porém os relacionamentos vão além, porque os relacionamentos tecem as redes de saber sobre o outro.

$\mathrm{Na}$ sociedade atual, as bases de dados digitais guardam grande quantidade de dados que podem ser automaticamente coletados, acessados, manipulados e remixados estão disponíveis em tempo real, são distribuídos em alta velocidade por todo o mundo, são fáceis e baratos de coletar e distribuir, e podem ser duplicados sem destruir o dado original.

$\mathrm{Na}$ vigilância digital, para gerar saber é necessário registrar e analisar as ações e comunicações na internet. A conexão poder/saber que Foucault ressalta como constitutiva para a vigilância assume a forma poder/dados digitais na era da informação (Fuchs 2011: 118). São estes dados digitais que contêm as informações necessárias para se gerar o saber sobre o outro. E, mais uma vez, poucos podem vigiar muitos. Poucas são as companhias que detêm o controle sobre as comunicações digitais realizadas por milhões de usuários. Estas detêm o poder do acesso à informação; e, as informações coletadas, por sua vez, são efetivamente usadas pelos governos e por empresas da 
iniciativa privada, que também representam um contingente pouco numeroso, a receber os dados de um grande número de pessoas.

A vigilância digital se utiliza da própria arquitetura da rede que, por ela mesma, favorece a vigilância. Todas as informações passam por servidores, que são os nós da rede. Entre o emissor e o receptor da informação, a mensagem eletrônica encontra vários nós. Em cada um deles, ela pode ser interceptada, coletada e armazenada.

Na sociedade contemporânea, poucos vigiam muitos. Ainda temos uma vigilância absolutamente discreta, que precisa não ser detectada para bem funcionar. A vigilância atua através dos próprios mecanismos que viabilizam a utilização da internet pelos usuários (Bruno 2006: 154). O uso da internet permite aos indivíduos gerar informação e deixar rastros passíveis de serem vigiados. A mesma tecnologia que permite enviar mensagens e postar fotos e vídeos é utilizada para interceptar o conteúdo e exercer a vigilância.

Atualmente, a vigilância se dá nos rastros que os indivíduos deixam ao acessar dados digitais na internet, de forma contínua e automática. As informações são recolhidas, por meio de dispositivos digitais. O controle acontece sem a necessidade da presença e do contato físico entre observador e observado.

Somos vigiados e, permanentemente, avaliados. É o que na prática fazemos a todo minuto: avaliamos, julgamos e ranqueamos serviços, governos, parceiros e, até a nós mesmos. A todo instante o nosso desempenho é avaliado. Somos incitados a declarar nossa performance social e privada. Por outro lado, atualmente os atores sociais, individuais e coletivos, podem publicizar suas opiniões e demandas sem a necessidade da mediação das organizações midiáticas tradicionais, já que os processos de visibilidade e legitimidade institucionais estão hoje perpassados por uma lógica, na qual podem ser identificadas inúmeras possibilidades interativas e fluxos comunicacionais, que se constituem em um vigoroso local de estudo para a área.

Os processos de visibilidade e legitimidade passam a ser também apreendidos por meio do "olhar" dos serviços de busca/buscadores. O investimento em algoritmos, pelas empresas responsáveis por mecanismos de busca, é constante, pois eles são responsáveis pela "varredura" de páginas na Web e, como têm caráter mercadológico, possuem lógicas próprias, sendo algumas confidenciais. Porém, suas funções básicas são pesquisar, relacionar, entrar em diretórios e subdiretórios e decifrar linguagens e instruções nas páginas Web.

$\mathrm{O}$ atual contexto permite ultrapassar o entendimento do processo de legitimação como determinado pelo olhar dos outros e atentar, especialmente, para o relacionamento com esses outros, que podem estar inseridos em novos fluxos e possibilidades de interação. Não basta estar visível, é preciso interagir. A questão posta hoje é a ampliação das possibilidades interativas entre os sujeitos e a multiplicidade de fluxos de comunicação.

Admitir que vivemos em um espaço de relações, e que estas definem a posição dos agentes, permite pensar os processo de visibilidade e de legitimidade a partir de algumas das características da sociedade atual, onde as lógicas midiáticas, da mesma forma que os gases, parecem ocupar totalmente as ambiências. Destaco aqui as novas possibilidades de interação à distância proporcionadas pelas tecnologias de informação e comunicação e a nova lógica espaço-temporal, na qual os espaços locais, regionais, nacionais e internacionais são mobilizados por ações transversais, que 
redefinem as possibilidades estratégicas de ação e denotam uma constante hibridação entre esses espaços.

É possível considerar que existem proximidades evidentes, mas também diferenças significativas, entre o pensamento de Foucault sobre a vigilância moderna e as formas de vigilância digital que atuam na sociedade contemporânea. Se analisarmos características apontadas por Foucault (1996) sobre a vigilância moderna, é possível relacioná-las, mas também estabelecer contrapontos, ao que se processa com a vigilância nos dias de hoje. Com relação à característica da vigilância como um olhar que vê sem ser visto, pode-se dizer que a vigilância atual também opera da mesma forma, quando aquele que vigia busca não ser visto e nem percebido (Bruno 2006).

Quanto menos a vigilância for percebida como algo existente dentro do próprio sistema de comunicação digital, mais autenticidade haverá nas informações que poderão ser coletadas. Não ser visto é uma estratégia que garante a autenticidade do conteúdo informacional colhido. Todas as comunicações realizadas por meio digital, especialmente, por meio dos grandes controladores de sites de comunicação e relacionamento, estão passíveis de serem coletadas e armazenadas. Quem detém a tecnologia detém também o poder sobre ela e sobre as operações realizadas por meio delas. O usuário nem sempre percebe, mas a possibilidade da vigilância ocorrer é real. E a vigilância digital também opera por meio de vigilâncias múltiplas e entrecruzadas. Os usuários de internet geralmente se valem dos serviços de duas ou mais empresas que controlam o mercado de comunicação, ao fazerem uso dos serviços de telefonia móvel, mensagens eletrônicas, sites de redes sociais, compartilhamento de fotos e vídeos. As informações coletadas podem ser correlacionadas e gerar perfis computacionais (Bruno 2006), que permitem a elaboração de um saber sobre o outro.

Porém, esta nova forma de vigiar prescinde da presença física entre observador e observado, uma vez que se utiliza dos dispositivos tecnológicos de comunicação que rastreiam as marcas deixadas pelos internautas e abastecem bancos de dados onde estas informações são correlacionadas entre si, gerando um saber sobre os outros.

\section{Os meios como ambientes culturais na ecologia midiática}

A Media Ecology tem na sua origem a presença do controverso pensador canadense McLuhan (1962, 1964), autor do aforismo "o meio é a mensagem". Em conjunto, os meios formam um ecossistema, indo além de sua materialidade técnica. Esta abordagem tem crescido na atualidade, em função da aproximação de muitos dos seus pressupostos ao estudo, da era digital. O destaque dado aos meios, na perspectiva ecológica, supera o determinismo tecnológico, ao levar em conta não apenas as materialidades das mídias, mas incluir suas linguagens, lógicas, processos sociais e culturais.

Foi o pesquisador norte americano Neil Postman que institucionalizou a Media Ecology como campo científico, durante uma conferência em Nova York, em 1968. Três anos depois, ele fundou o primeiro programa de estudos na área, na New York University. Em 1998, ex-alunos de Postman fundaram a Media Ecology Association, em Nova York (MEA), cujos postulados centrais permanecem nos estudos sobre as transformações dos meios de comunicação no atual ecossistema digital (Scolari 2010, 2012). 
Os pressupostos da Media Ecology podem ser resumidos em duas ideias centrais: a) os meios de comunicação constituem um entorno (o medium como ambiência) que modifica nossa percepção e nossa cognição; b) os meios são as espécies que vivem em um ecossistema e estabelecem relações entre si e com os sujeitos que nele interagem (Scolari 2010). Ou seja, um meio não opera apenas no nível da mediação entre o sujeito e o mundo, pois cria, por meio de lógicas e códigos específicos, uma forma diferente de relação entre os sujeitos e o mundo. Essa forma de relação pode ser interpretada como o processo que tem sido denominado como midiatização, resultante da exacerbação das múltiplas mediações operadas pelas tecnologias de comunicação e informação.

O termo ecossistema (do grego, oikos) refere-se ao ambiente no qual se vive. A noção de ecossistema, aplicada à mídia, ajuda a compreender como as modificações em cada meio ou no ambiente interferem no conjunto e impactam também as partes que o constituem.

Segundo o paradigma teórico da Ecologia da Mídia (Postman 2000), os meios de comunicação constituem um entorno sócio-técnico e cultural, relacionando-se entre si como em um ecossistema. A introdução de novas espécies e os novos usos de meios antigos, por exemplo, interferem no sistema midiático como um todo.

Atualmente, as novas espécies são representadas, no ecossistema midiático, pelas plataformas de redes sociais. As redes sociais da internet são constituídas pelos atores sociais, suas representações on-line e as interações que eles estabelecem entre si. Essas redes são construídas ou mantidas a partir de plataformas digitais, ou seja, sites de redes sociais ou outras mídias digitais apropriadas como tal (Recuero 2010). Elas integram o complexo ecossistema midiático atual, que tem nas tecnologias digitais sua matriz de operação.

A reconfiguração do ecossistema midiático, trazida pela era digital, interfere nas lógicas pela quais as organizações, inclusive as midiáticas, se comunicam, se constituem e se legitimam perante a sociedade. No atual ecossistema, é esperado das organizações midiáticas que elas participem do diálogo e se apropriem das potencialidades dos diferentes meios tecnológicos, desencadeando a convergência midiática em toda a sua plenitude; seja distribuindo conteúdo por diferentes plataformas, ingressando em novos segmentos da informação e do entretenimento por meio da promoção de narrativas transmídia, perpassando todas as esferas do ecossistema midiático, que passa a atuar como matriz de práticas sociais e comunicacionais.

A perspectiva ecológica pode ajudar a compreender o desempenho de atores individuais e coletivos, tecnologias de distribuição de informação, meios de comunicação interpessoais e coletivos. $\mathrm{O}$ atual contexto permite ultrapassar o processo de comunicação como algo estanque, formado por emissores, receptores e "canais".

O paradigma da Ecologia da Mídia pode permitir um novo olhar para o relacionamento com os outros, os interagentes da comunicação, que podem estar inseridos em novos fluxos e possibilidades de interação. Atualmente, a questão posta é a ampliação das possibilidades interativas entre os sujeitos e a multiplicidade de fluxos de comunicação, proporcionados, especialmente, pela mídia digital e sua relação com a constante reconstrução das culturas e dos indivíduos.

\section{Últimos comentários}

a) O princípio do panoptismo ainda vigora. Atualmente, poucos ainda vigiam muitos 
Os sujeitos que detêm o saber, que acessam estas informações, detêm também o poder sobre os demais atores sociais. Em nome de interesses mais amplos, interferem em questões como a privacidade, por exemplo. Na maioria das vezes os indivíduos não se dão conta da vigilância. Ela opera nos rastros, nas marcas deixadas pelo internauta e este não percebe que está sendo vigiado, que suas ações na internet estão sendo olhadas e avaliadas. A vigilância hoje, ainda, é panóptica, não porque as tecnologias de vigilância estejam centralizadas e hierarquizadas, conforme ditam os princípios do panoptismo, mas porque o Estado e as empresas são os atores dominantes e acumulam poder (Fuchs 2011: 122).

b) A vigilância se dá pelo rastreamento das atividades na rede

As empresas têm objetivos publicitários e comerciais, rastreiam as preferências dos consumidores na internet para poderem oferecer, por meio de anúncios, aquilo que os indivíduos demonstram ter interesse ao visitar páginas, sites, blogs, redes sociais. Ao navegar na internet e fazer download de conteúdo, ficam os registros dos caminhos percorridos, das buscas realizadas, das preferências pessoais. Esses registros abastecem bancos de dados que ajudam a otimizar a oferta de produtos ou de serviços. Já o Estado visa o controle sobre questões de segurança, saúde pública, soberania nacional.

\section{c) Vigiar e ser vigiado}

No campo específico das organizações empresariais, percebe-se que existe a busca pela visibilidade, através do uso das novas tecnologias, ao mesmo tempo em que se dá o exercício de controle das informações que circulam neste ambiente. A contradição está entre usufruir das possibilidades tecnológicas e manter o controle das informações que circulam. Estão em jogo estratégias que buscam promover a visibilidade, ao mesmo tempo em que buscam garantir o controle e a vigilância. E são as novas tecnologias que se encontram imbricadas nesse processo e garantem a ubiquidade do exercício desse poder controlador.

A presença das organizações no ambiente on-line parece ser inevitável, pois elas são mencionadas por internautas independentemente de sua vontade ou iniciativa. Para exercer esta contravigilância existem programas que podem ser adquiridos pelas empresas para monitorar o que é dito sobre elas na internet. Cada vez que um internauta menciona a empresa, a mensagem chega também para a organização que pode interagir com o produtor do conteúdo. As empresas, percebendo a importância deste monitoramento, estão organizando suas assessorias de comunicação para incorporar esta nova tarefa, com a aquisição dos equipamentos e programas necessários e da contratação de pessoal capacitado a realizar este monitoramento e interagir com o usuário do sistema.

d) A ubiquidade dos media

Os meios de comunicação não são apenas tecnologias que as organizações, os partidos ou os indivíduos podem optar por utilizar - ou não utilizar - como bem entenderem. Eles se tornaram uma parte integral do funcionamento de outras instituições, embora também tenham alcançado um grau de autodeterminação e autoridade que leva essas instituições, em maior ou menor grau, a submeterem-se a sua lógica (Hjarvard 2012:54). A mídia tem determinado uma forma particular 
de comportamento das instituições sociais, que passam a incorporar, no seu fazer, procedimentos que são próprios do universo midiático.

Os discursos e as práticas são pensados para obedecer a critérios e aos modos de operacionalização da mídia. As mediações sociais destes outros campos passam a estar impregnadas e a funcionar de acordo com os estatutos midiáticos (Hjarvard 2012). A relação entre a mídia e o contexto cultural e social é marcada pela dualidade. Ao mesmo tempo em que a mídia faz parte da sociedade e da cultura, ela se coloca como uma instituição independente que se interpõe entre outras instituições e coordena a interação entre elas.

e) As redes sociais digitais e o reconhecimento do outro

A digitalização das redes social amplia as possibilidades de expressão e de comunicação entre os indivíduos, assim como foram também estendidas as formas de interação e relacionamento. São inúmeros os sites de redes sociais existentes hoje e, acredito que, o campo acadêmico foi lento para reconhecê-los como media. Atualmente, os acontecimentos são discutidos pelos indivíduos nas redes, passam pela mídia hegemônica, que ainda se constitui como local de legitimação e reconhecimento, para, então, ganhar as ruas em manifestações presenciais e depois voltarem às redes e, assim, é promovida uma circulação contínua.

f) A circulação dos acontecimentos pelo olhar da ecologia midiática

O entendimento dos meios como ambiências, turva a separação entre novos e velhos media e até mesmo a hierarquia entre eles, pois a atuação de cada meio vai mudar de acordo com a sua posição na ecologia midiática e com a interação entre os indivíduos. O conceito de sociotécnica é para mim central neste entendimento ao não separar a técnica da ação humana.

g) Os media como artefatos

Ao finalizar, ressalto que a perspectiva ecológica, centrada nos meios, ancora-se, neste trabalho, na aceitação de que falar nos media é compreendê-los por um prisma sociotécnico e cultural, como artefatos humanos.

\section{Referências}

Barichello, E.M.M.R. (2013). Ecologia da Mídia. Santa Maria: FACos/UfSM.

Berger, P. \& Luckmann, T. (1997). A construção social da realidade. Petrópolis: Vozes.

Bruno, F. (2006). Dispositivos de vigilância no ciberespaço: duplos digitais e identidades simuladas. Revista Fronteiras: 152-9. São Leopoldo.

Bruno, F. (2008). Monitoramento, classificação e controle nos dispositivos de vigilância digital. In H. Antoun (org.), WEB 2.0: participação e vigilância na era da comunicação distribuída (pp. 167-182). Rio de Janeiro: Mauad.

Canavilhas, J. (2015). Nuevos Medios, Nuevo Ecosistema. El Profesional de La Información, 24 (4): 357-362.

Canavilhas, J. (2014). Jornalismo Transmídia: um Desafio ao Velho Ecossistema Midiático. In Renó et al, Periodismo transmídia: miradas múltiples. Barcelona: UOC. 
Deleuze, G. (2013). Conversações. São Paulo: Ed 34.

Foucault, M. (1996). Vigiar e punir. Petrópolis: Vozes.

Fuchs, C. (2011). Como podemos definir vigilância?. Matrizes, jul./dez., 5 (1): 109-136. São Paulo.

Horst, H. \& Miller, D. (eds). (2012). The digital and the human: a prospectus for digital anthropology. Digital Anthropology: 3-36. Oxford: Berg.

Hjarvard, S. (2012). Midiatização: teorizando a mídia como agente de mudança social e cultural. Matrizes, jan.-jun., 5 (2): 53-91.

Mcluhan, M. (1962). The Gutenberg galaxy: the making of typographic man. Toronto: University Toronto Press.

Mcluhan, M. (1964). Understanding media: the extensios of man. New York: New American Library.

Miller, D. (2009). Antropology and the individual: a material culture perspective. Oxford, New York: Berg.

Miller, D. \& Slater, D. (2001). The internet: an etnographic approach. Oxford, New York: Berg.

Postman, N. (2000). The humanism of media ecology. Online. Disponível em: www.mediaecology.org.

Recuero, R. (2010). Redes sociais na internet. Porto Alegre: Sulina.

Scolari, C. A. (2010). Ecología de los medios. Mapa de un nicho teórico. Quaderns del CAC, jun, XIII (1): 17-25.

Scolari, C. A. (2012). Media ecology: exploring the metaphor to expand the theory. Comunication Theory, 22: 204-225.

Pereira, V. A. (2004). As tecnologias de comunicação como gramáticas: meio, conteúdo e mensagem na obra de Marshall McLuhan. Revista Contracampo, 10/11: 7-20.

Rodrigues, A. D. \& Braga, A. (2014). A natureza midiática da experiência. In Barreto, E. et al, Mídia, Tecnologia e Linguagem Jornalística, João Pessoa, Editora do CCTA.

Steimberg, J. (2014). Misbehavior in mediated places: situational proprieties and communication environments. In E. Barichello \& A. Rubleski (org.), Ecologia da Mídia. Santa Maria: FACOS-UFSM.

Vizer, E. (org.) (2012). Lo que Mcluhan no predijo. Prólogo de Derrick de Kerkhove. Buenos Aires: La Crujia. 